Marquette University

e-Publications@Marquette

4-1-1995

Monetary Policies in Interdependent Economies: An Open Economy Explanation for Base Drift and Price-Level Non-Trend-Stationarities

Joseph Daniels

Marquette University, joseph.daniels@marquette.edu

David D. VanHoose

University of Alabama - Tuscaloosa

Accepted version. Journal of International Money and Finance, Vol. 14, No. 2 (April 1995): 275-287.

DOI. Published under Creative Commons license Attribution-NonCommercial-NoDerivatives 4.0 International. 


\title{
Monetary Policies in Interdependent Economies: An Open Economy Explanation for Base Drift and Price-Level Non-Trend-Stationarities
}

\author{
By Joseph P. Daniels and David D. VanHoose
}

Most nations have experienced 'base drift' of their money stocks and associated price-level non-trend-stationarities. Recent explanations for this fact have emphasized tensions among various possible objectives of central banks in closed-economy or small-open-economy frameworks. In contrast, this paper explores structural and policy interdependence among economies as an explanation for price-level non-trend-stationarities. It demonstrates that such interdependence can induce central banks to follow non-trend-stationary policies even if they desire only to smooth prices in their home economies.

Growing integration of economies throughout the world has led to increased interest in the international implications of monetary policies for the behavior of key macroeconomic variables such as employment, output or prices. While much interest has been focused specifically on coordination issues that have arisen in Europe, there has been a growing recognition that even the traditionally 'closed' USA economy can no longer be examined in isolation from influences originating in other economies. This paper focuses on providing an explanation of how central bank policymaking may produce price-level non-trend-stationarities when countries' output markets are interdependent.

Base drift of monetary aggregates and price-level non-trend-stationarity have been conspicuous features of the macroeconomic time series of many countries in the world. Critics argue that a central bank policy that permits base drift is inconsistent with an objective of price-level stabilization in the long run, as evidenced by the observed non-trend-stationarities of consumer prices. In the USA, the Federal Reserve System has long been criticized for allowing base drift to occur. In addition, Bordo, Choudhri and Schwartz (1990) recently have argued that the variance of trend inflation in the UK could have been more than 50 percent smaller in the absence of base drift in that country.

Recent closed-economy work by Walsh $(1986,1990)$ and Goodfriend $(1987,1991)$ has helped delineate key issues concerning base drift and price-level non-trend-stationarity. Walsh's (1986) work helps answer criticisms of base drift by clarifying conditions under which non-trend-stationarity of a monetary aggregate may be necessary to eliminate non-trend-stationarity of the price level, while Goodfriend's (1987) analysis formalizes and 
buttresses the arguments of the critics of central bank policies. Specifically, Goodfriend has argued that, barring permanent shocks of the type considered by Walsh, trend-stationarity of the nominal money stock, and consequently of the price level, is fully consistent with a price-smoothing objective of a monetary authority, where the price-smoothing objective is defined as minimization of a weighted average of the variances of price-level prediction errors and of anticipated inflation. Goodfriend further demonstrates that base drift and price-level non-trend-stationarity emerge when central banks desire to smooth interest rates as well as prices. He argues that a goal of interest-rate smoothing thereby represents an explanation for why the conduct of monetary policies by central banks around the world generates monetary and price-level non-trend-stationarities.

VanHoose (1989) has countered this argument by using an extended version of Goodfriend's closed-economy model to show that, in fact, a central bank objective of interest-rate smoothing is a sufficient, but unnecessary, condition for these outcomes to arise in a closed-economy context. In VanHoose's analysis, monetary policy is conducted to achieve a target quantity of money or, alternatively, to smooth variability around a target money stock. Under either interpretation of intermediate monetary targeting, VanHoose demonstrates that base drift and non-trend-stationarity of the price level generally are optimal policy outcomes when central banks desire to smooth prices. The fundamental reason for this result is that, by committing itself to the additional objective of targeting a monetary aggregate, a central bank loses a degree of freedom in its ability to aim its monetary instruments independently at its price variance objectives. Consequently, VanHoose helps clarify one fundamental explanation for nontrend-stationarity of money and prices, which is that it may arise from a shortfall in available instruments relative to desired targets. Under this perspective on the issue, addition of any objective to that of price stabilization, whether it be interest-rate smoothing or monetary smoothing, confounds the ability of a central bank to generate monetary and price-level trend-stationarity.

Sephton (1989) has extended the list of objectives that potentially could lead to this policy outcome by considering an open-economy environment. Sephton examines a small-country model with flexible exchange rates and perfect capital mobility. In the context of this model, he shows that domestic price-level and exchange-rate non-trend-stationarities generally result when the country's central bank pursues an exchange-rate-smoothing objective in conjunction with a price-smoothing goal. Sephton's work essentially is a direct extension of Goodfriend's interest-rate smoothing result to a case in which exchange-rate smoothing, rather than interest-rate smoothing, is an added central bank objective. 
This paper also evaluates international-based explanations for non-stationarities evidenced in macroeconomic time series. Unlike other work on this topic, however, the analysis conducted in this paper explores the possibility that price-level non-trend-stationarities may emerge solely from structural linkages between interdependent economies. We argue that international interdependence produces inherent spillover effects that can induce central banks to conduct monetary policies that promote non-trend-stationarity paths for money and prices, even if they solely pursue price-smoothing objectives.

The paper is organized as follows. Section I lays out and discusses a general two-economy model that is the foundation for our analysis. For the sake of expositional clarity, however, we emphasize a specific, restricted case of the general model, which we discuss and analyze in Section II. We show, using this special case of the general two-country framework, how non-trend-stationary monetary policies can arise from central bank policymaking in an open-economy environment. In Section III, we demonstrate that central banks can pursue trend-stationary policies by optimally conditioning their money supply rules to foreign money stock innovations. Section IV summarizes our results and their implications for further research.

\section{A Model of Interdependent Economies}

The model that follows is an extension of Turnovsky et al. (1988) and Turnovsky and d'Orey's (1989) two-country, flexible-exchange-rate model that includes policy rules of the type considered by Goodfriend (1987). The equations for the model are as follows:

$$
\begin{aligned}
& <1> \\
& p_{t}^{c}=\alpha p_{t}+(1-\alpha)\left(p_{t}^{*}+e_{t}\right) ; 1 / 2<\alpha<1, \\
& <1 \text { '> } \\
& p_{t}^{c^{*}}=\alpha p_{t}^{*}+(1-\alpha)\left(p_{t}+e_{t}\right) \\
& <2> \\
& y_{t}=c y_{t}^{*}-d_{1}\left[r_{t}-\left(E_{t} p_{t+1}^{c}-p_{t}^{c}\right)\right]+d_{2}\left(p_{t}^{*}+e_{t}-p_{t}\right)+d_{3} p+d_{4} \eta_{t} \text {, } \\
& 0 \leq c \leq 1 ; d_{1}, d_{2}, d_{3}, d_{4} \geq 0 \\
& <2 \text { '> } \\
& <3> \\
& <3 \text { '> } \\
& <4> \\
& <5> \\
& <5 \text { '> } \\
& <6> \\
& <6 \text { '> } \\
& y_{t}^{*}=c y_{t}-d_{1}\left[r_{t}^{*}-\left(E_{t} p_{t+1}^{c^{*}}-p_{t}^{c^{*}}\right)\right]+d_{2}\left(p_{t}^{*}+e_{t}-p_{t}\right)+d_{3} p+d_{4} \eta_{t} \\
& m_{t}-p_{t}=y_{t}-b r_{t}+\xi_{t} ; \quad b \geq 0 \text {, } \\
& m_{t}^{*}-p_{t}^{*}=y_{t}^{*}-b r_{t}^{*}+\xi_{t}^{*} \\
& r_{t}=r_{t}^{*}+E_{t} e_{t+1}-e_{t} \text {, } \\
& y_{t}=a\left(p_{t}-E_{t-1} p_{t}\right) ; a \geq 0 \text {, } \\
& y_{t}^{*}=a\left(p_{t}^{*}-E_{t-1} p_{t}^{*}\right), \\
& m_{t}=m_{t-1}+\theta_{1}\left(r_{t}-E_{t-1} r_{t}\right)-\theta_{2}\left(m_{t-1}-E_{t-2} m_{t-1}\right), \\
& m_{t}^{*}=m_{t-1}^{*}+\theta_{1}^{*}\left(r_{t}^{*}-E_{t-1} r_{t}^{*}\right)-\theta_{2}^{*}\left(m_{t-1}^{*}-E_{t-2} m_{t-1}^{*}\right) \text {, }
\end{aligned}
$$


where domestic variables and policy parameters are non-asterisked and foreign variables are asterisked with

$$
\begin{aligned}
& p_{t} \equiv \text { log of the price level, } \\
& e_{t} \equiv \text { log of the exchange rate, measured in terms of units of domestic currency per unit } \\
& \text { of foreign currency, } \\
& y_{t} \equiv \text { log of real output, } \\
& r_{t} \equiv \text { nominal interest rate, } \\
& m_{t} \equiv \text { log of the nominal money stock, } \\
& E_{t+j} \equiv \text { expectation operator, conditional on information dated time } t+j, \\
& \eta_{t} \equiv \text { domestic output demand disturbance, with } E\left(\eta_{t}\right)=0 \text { and } E\left(\eta_{t}^{2}\right)=\sigma_{\eta}^{2}, \\
& \eta_{t}^{*} \equiv \text { foreign output demand disturbance, with } E\left(\eta_{t}^{*}\right)=0 \text { and } E\left(\eta_{t}^{* 2}\right)=\sigma_{\eta^{*}}^{2}, \\
& \xi_{t} \equiv \text { domestic money demand disturbance, with } E\left(\xi_{t}\right)=0 \text { and } E\left(\xi_{t}^{2}\right)=\sigma_{\xi}^{2}, \\
& \xi_{t}^{*} \equiv \text { foreign money demand disturbance, with } E\left(\xi_{t}^{*}\right)=0 \text { and } E\left(\xi_{t}^{* 2}\right)=\sigma_{\xi^{*}}^{2},
\end{aligned}
$$

and $\rho$ is a constant. All disturbances are independently distributed and are serially uncorrelated.

Equations $<1>$ and $<1$ '> are consumer price indexes for the domestic and foreign economies, respectively, where $\alpha$ is the weight on consumption of home goods. The exchange rate is assumed to be perfectly flexible throughout the analysis. Equation $<2>$ is the equilibrium condition for the domestic goods market, in which domestic output demand generally depends positively upon foreign income, negatively upon the domestic real interest rate, computed in terms of the domestic CPI, and positively on the relative price of foreign output. Equation $<2$ ' $>$ is the equilibrium condition for the foreign goods market, which mirrors equation <2> except for the offsetting relative price effect.

Equations <3> and <3'> are demand functions for real money balances for the two economies. The income elasticity of money demand is assumed to be unity as a simplification that has no qualitative effects on our results. This simplification implies that only the home price level enters the money demand functions even though consumer prices otherwise influence demand-side behavior. Equation $<4>$ is the uncovered interest rate parity condition that arises if domestic and foreign bonds are perfect substitutes. Equations $<5>$ and $<5$ ' $>$ are typical 'price-misperception' aggregate output supply functions for the two economies (with output normalized around trend). Aggregate supply disturbances could be included in $<5>$ and $<5$ '> without affecting the basic thrust of the analysis, and so we have elected not to include supply shocks in our exposition. As in Turnovsky et al., Turnovsky and d'Orey, and many other two-country settings, we assume that home price prediction errors influence home supply-side 
behavior, which holds strictly if labor is immobile between countries and if labor supply is perfectly inelastic with respect to the real wage.

Finally, equations $\langle 6\rangle$ and $\left\langle 6^{\prime}\right\rangle$ are money supply rules for the central banks of the domestic and foreign economies. The parameters $\theta_{1}$ and $\theta_{1}^{*}$ are Poole-type (1970) combination policy instruments that determine the central banks' degrees of responsiveness of their money stocks to innovations in nominal interest rates. If $\theta_{2}=\theta_{2}^{*}=1$, the money stocks for both countries follow trend-stationary paths, while a departure from unity for $\theta_{2}$ or $\theta_{2}^{*}$ implies a non-trend-stationary path for the domestic money stock or foreign money stock, respectively. Although this is a simplified money supply rule, it allows us to focus on the trend-stationarity issue.

As often is the case in models of this type, the computation of full reduced-form analytical solutions to the general model leads to solutions that are not readily amenable to policy analysis. There are two basic options for addressing this problem. One approach, followed by Basar et al. (1986) and Turnovsky and d'Orey (1986, 1989), is to study numerical simulations of the general model. An alternative approach, which is more consistent with the expositional intentions of this paper, is to consider special cases of the general framework that lend themselves to analytical solutions suitable for policy analysis. For instance, in his dosed-economy model, Goodfriend (1987) considers the case in which $d_{1}, d_{3}$ and $d_{4}$ approach infinity. For this case, equations $<2>$ and $<2$ '> collapse to interest-arbitrage relationships (that is, Fisher equations). Specifically, $<2>$ then reduces to $r_{t}=r_{t}^{*}+E_{t} p_{t+1}^{c}-p_{t}^{c}+\eta_{t}$, and $<2^{\prime}>$ becomes $r_{t}^{*}=r_{t}+E_{t} p_{t+1}^{c^{*}}-p_{t}^{c^{*}}+\eta_{t}^{*}$, so that the IS schedules for both economies are horizontal.

This particular special case is unsuitable for our purposes, however, because combining such simplified domestic interest-arbitrage relationships with international interest arbitrage yields ex ante purchasing power parity and thereby eliminates most of the international linkages otherwise present in an open-economy environment. Consequently, policy analysis in the following section focuses on an alternative version of the model that permits short-run ex ante and ex post departures from purchasing power parity to occur and that also yields tractable policy solutions.

Following Goodfriend (1987), we assume throughout the analysis that the key objective of the domestic monetary authority is 'price smoothing'. The monetary authority smooths prices by minimizing a weighted sum of the variance of home price prediction errors, perhaps because of an interest in smoothing output, and the variance of anticipated consumer price inflation, so as to save private agents the costs of indexing nominal contracts. Therefore, the domestic loss is given by 


$$
L=\beta_{1} \operatorname{Var}\left(p_{t}-E_{t-1} p_{t}\right)+\beta_{2} \operatorname{Var}\left(E_{t} p_{t+1}^{c}-p_{t}^{c}\right)
$$

Likewise, the foreign central bank desires to minimize the loss function,

$$
<7^{\prime}>\quad L^{*}=\beta_{1}^{*} \operatorname{Var}\left(p_{t}^{*}-E_{t-1} p_{t}^{*}\right)+\beta_{t}^{*} \operatorname{Var}\left(E_{t} p_{t+1}^{c^{*}}-p_{t}^{c^{*}}\right) .
$$

Throughout our analysis, we assume further that the central banks do not coordinate their price-smoothing policies. Hence, the domestic authority sets $\theta_{1}$ and $\theta_{2}$ to minimize $<7>$ without regard to the decisions of the foreign central bank, which independently minimizes $\left\langle 7^{\prime}>\right.$ via its choices of $\theta_{1}^{*}$ and $\theta_{2}^{*}$. Certainly, in principle the two central banks could coordinate their policies by choosing the values of the four policy parameters that simultaneously minimize (7) and ( $\left.7^{\prime}\right)$. For purposes of this paper, however, it is assumed that policy strategies are not coordinated, perhaps because of a lack of trust or an inherent public sentiment against coordinating policies in one or both of the countries (see Cooper, 1985, for a discussion of these issues).

\section{Monetary Policies and Non-Trend-Stationarities in a Simplified Version of the Model}

Because general solutions to the full model are not readily amenable to (long-hand or computer-assisted) policy analysis, we explore the model's policy implications in the context of a simplified version of the model. One simplification we make is to set $d_{2}$ equal to zero, so that there are no relative price effects on desired expenditures. We also normalize $d_{4}$ at a value of unity. Finally, we consider the case in which $a=0$, which implies that the countries' aggregate supply schedules become perfectly inelastic. This can be interpreted either as a limiting case of the model or as a case in which the central banks pursue a general objective of intertemporal price smoothing, with no specific interest in output smoothing per se.

Of the restrictions that we impose, the last is the most substantive, because it limits considerably the scope for feedbacks of shocks via short-run effects that they otherwise would induce upon production in each economy. Yet adopting these simplifying restrictions does not affect our basic conclusions, because structural interdependence between the two countries continues to arise through the effects that variations in anticipated consumer price inflation exert on real interest rates. For instance, a domestic money demand shock causes a change in anticipated consumer price inflation in the foreign economy, thereby altering the foreign real interest rate and causing a change in foreign desired expenditures.

To solve the model, equilibrium conditions for the domestic output and money markets 
and for the foreign money market are used to solve for the endogenous variables $p_{t}, p_{t}^{*}, r_{t}$, and $r_{t}^{*}$. Proposed solutions for these variables are expressed as linear functions of the disturbances $\eta_{t}, \eta_{t}^{*}, \xi_{t}$, and $\xi_{t}^{*}$ of the lagged money stocks, $m_{t-1}$ and $m_{t-1}^{*}$, and monetary innovations, $m_{t-1}-E_{t-2} m_{t-1}$ and $m_{t-1}^{*}-E_{t-2} m_{t-1}^{*}$ in terms of undetermined coefficients. Solutions for the four sets of undetermined coefficients are obtained from the four-equation general equilibrium coefficient restrictions that are implied. The procedure for obtaining these solutions and the complete solutions for the unrestricted model are detailed in an appendix that is available from the authors upon request.

It turns out that we can make our essential points without considering all four types of shocks simultaneously; all that is required is to consider the implications of concurrent domestic and foreign disturbances. Hence, we make one final assumption, which is that $\eta_{t}=\xi_{t}^{*}=0$ for all $t$, so that $\sigma_{\eta}^{2}=\sigma_{\xi^{*}}^{2}=0$. That is, we assume that the domestic economy experiences only money demand disturbances $\left(\sigma_{\xi}^{2}>0\right)$ and that the foreign economy experiences only real expenditure shocks $\left(\sigma_{\eta^{*}}^{2}>0\right)$.

Under these restrictions, the variance of the domestic price prediction error is equal to

$<8>$

$$
\operatorname{Var}\left(p_{t}-E_{t-1} p_{t}\right)=\left[d_{1}^{2}(1-2 \alpha)^{2}\right]^{-1}\left[(1-\alpha)^{2}(1-A)^{2} \sigma_{\eta^{*}}+d_{1}^{2}(1-2 \alpha)^{2} A^{2} \sigma_{\xi}^{2}\right],
$$

where $A \equiv\left\{\left(\theta_{1}+b\right)+\left[1-\left(1-\theta_{2}\right) \theta_{1}\right]\right\}^{-1}\left[1-\left(1-\theta_{2}\right) \theta_{1}\right]$, and the variance of domestic anticipated inflation is given by

$<9>\quad \operatorname{Var}\left(E_{t} p_{t+1}^{c}-p_{t}^{c}\right)=\left[d_{1}^{2}(1-2 \alpha)^{2}\right]^{-1} B^{2}\left[(1-\alpha)^{2} \theta_{\eta^{*}}^{2}+d_{1}^{2}(1-2 \alpha)^{2} \sigma_{\xi}^{2}\right]$,

where $B \equiv\left\{\left(\theta_{1}+b\right)+\left[1-\left(1-\theta_{2}\right) \theta_{1}\right]\right\}^{-1}$.

For the foreign country, the variance of price prediction errors is given by $<10>$

$$
\operatorname{Var}\left(p_{t}^{*}-E_{t-1} p_{t}^{*}\right)=\left[d_{1}^{2}(1-2 \alpha)^{2}\right]^{-1}\left(A^{*}\right)^{2} \alpha^{2} \sigma_{\eta^{*}}^{2}
$$

where $A^{*} \equiv\left\{\left(\theta_{1}^{*}+b\right)+\left[1-\left(1-\theta_{1}^{*}\right) \theta_{2}^{*}\right]\right\}^{-1}\left(\theta_{1}^{*}+b\right)$, and the variance of anticipated consumer price inflation is equal to

$<11>\quad \operatorname{Var}\left(E_{t} p_{t+1}^{* c}-p_{t}^{* c}\right)=\left[d_{1}^{2}(1-2 \alpha)^{2}\right]^{-1}\left[(1-2 \alpha)+\alpha B^{*}\right]^{2} \sigma_{\eta^{*}}^{2}$,

where $B^{*} \equiv\left\{\left(\theta_{1}^{*}+b\right)+\left[1-\left(1-\theta_{2}^{*}\right) \theta_{1}^{*}\right]\right\}^{-1}$.

Minimization of these variances requires that $\hat{A}=\left[(1-\alpha)^{2} \sigma_{\eta^{*}}^{2}+d_{1}^{2}(1-2 \alpha)^{2} \sigma_{\xi}^{2}\right]^{-1}(1-$ $\alpha)^{2} \sigma_{\eta^{*}}^{2}, \hat{B}=0, \hat{A}^{*}=0$, and $\hat{B}^{*}=\alpha^{-1}(2 \alpha-1)$. It follows from the definitions of $A, B, A^{*}$, and $B^{*}$ that the solutions for the optimal policy parameters are given by 


$$
\begin{gathered}
\hat{\theta}_{1}=\infty, \\
\hat{\theta}_{2}=1+\left[d_{1}^{2}(1-2 \alpha)^{2} \sigma_{\xi}^{2}\right](1-\alpha)^{2} \sigma_{\eta^{*}}^{2}, \\
\hat{\theta}_{1}^{*}=-b, \\
\hat{\theta}_{2}^{*}=1-[b(2 \alpha-1)]^{-1}(1-\alpha) .
\end{gathered}
$$$$
<12>
$$$$
<13>
$$$$
<13^{\prime}>
$$

These choices yield zero loss levels for both authorities. The solutions in $\left\langle 12^{\prime}\right\rangle$ and $\left\langle 13^{\prime}\right\rangle$ imply that monetary and price-level non-trend-stationarity are optimal policy outcomes in both countries. Hence, non-trend-stationarities of money stocks and prices emerge even though both monetary authorities desire only to smooth home goods prices and home consumer prices.

The intuition behind the results in equations $\langle 12\rangle$ and $\langle 13\rangle$ is straightforward. Consider first the situation faced by the foreign monetary authority. The foreign authority's loss function can be written in the following form:

$<14>$

$$
\begin{gathered}
L^{*}=\beta_{1}^{*} \operatorname{Var}\left(p_{t}^{*}-E_{t-1} p_{t}^{*}\right)+\beta_{2}^{*} \operatorname{Var}\left[\alpha\left(E p_{t+1}^{*}-p_{t}^{*}\right)+(1-\right. \\
\left.\alpha)\left(E_{t} p_{t+1}-p_{t}\right)-(1-\alpha)\left(E_{t} e_{t+1}-e_{t}\right)\right] .
\end{gathered}
$$

Consequently, the foreign authority's two-part objective effectively has four separate components: (1) the foreign price-prediction error, $p_{t}^{*}-E_{t-1} p_{t}^{*}$; (2) foreign anticipated inflation, $E_{t} p_{t+1}^{*}-p_{t}^{*}$; (3) domestic anticipated inflation, $E_{t} p_{t+1}-p_{t}$; and (4) anticipated exchange-rate depreciation, $E_{t} e_{t+1}-e_{t}$. In our restricted version of the model, the third component cannot be influenced by the foreign authority, because foreign policy parameters have no effect on $E_{t} p_{t+1}-p_{t}$ (see equation $<9>$ ).

As indicated by equations $\left\langle 10>\right.$ and $\left\langle 11>\right.$, domestic money demand disturbances $\left(\xi_{t}\right)$ have no effect on the foreign loss. The reason is that domestic money demand shocks cause offsetting changes in anticipated domestic price inflation and in the two-country interest-rate differential. Because of uncovered interest parity, the interest-rate differential is equal to anticipated exchange-rate depreciation, and so domestic money demand shocks' effects on foreign consumer price inflation, which otherwise would be caused by induced variations in anticipated domestic price inflation, are exactly offset by variations in anticipated exchange-rate depreciation. On net, therefore, the foreign real interest rate is unaffected by domestic money demand disturbances, and so this particular channel of international interdependence is non-existent in our restricted version of the model.

By setting $\hat{\theta}_{1}^{*}=-b$, the foreign authority makes the foreign economy's $L M$ schedule vertical, which automatically offsets the effects on foreign aggregate demand that otherwise 
would arise as a result of foreign expenditures (IS) shocks $\left(\eta_{t}^{*}\right)$. This policy setting eliminates the effects of foreign IS shocks on foreign price prediction errors. Nevertheless, the foreign IS disturbance has non-offsetting effects on foreign anticipated inflation and the international interest-rate differential, and so the policy parameter $\theta_{2}^{*}$ must be aimed simultaneously at two separate objectives: $E_{t} p_{t+1}^{*}-p_{t}^{*}$ and $E_{t} e_{t+1}-e_{t}$. The trend-stationary setting $\hat{\theta}_{2}^{*}=1$ generally cannot satisfy both objectives simultaneously, unless $\alpha=1$, so that international interdependence vanishes. Therefore, international interdependence creates a tension among policy objectives that makes trend-stationary policymaking suboptimal for the foreign authority.

Note from $\left\langle 13^{\prime}>\right.$ that optimal foreign policymaking entails setting $\hat{\theta}_{2}^{*}>1$, so that the foreign monetary authority must decrease the money stock in the next period by more than any required contemporaneous increase. Consequently, agents anticipate foreign price deflation the next period. At the same time, however, agents anticipate foreign currency depreciation. The optimal setting for $\hat{\theta}_{2}^{*}$ in $<13^{\prime}>$ ensures that the anticipated foreign price deflation and foreign currency depreciation exactly offset one another in their effects on expected foreign consumer price inflation, so that no foreign consumer price inflation is anticipated.

Now consider the policy problem and its solution from the domestic authority's perspective. The domestic authority's loss function may be rewritten as $<15>$

$$
\begin{gathered}
L=\beta_{1} \operatorname{Var}\left(p_{t}-E_{t-1} p_{t}\right)+\beta_{2} \operatorname{Var}\left[\alpha\left(E_{t} p_{t+1}-p_{t}\right)+(1-\right. \\
\left.\alpha)\left(E_{t} p_{t+1}^{*}-p_{t}^{*}\right)+(1-\alpha)\left(E_{t} e_{t+1}-e_{t}\right)\right] .
\end{gathered}
$$

Therefore, the domestic monetary authority also effectively seeks to minimize a loss function that contains four elements. Although it views foreign anticipated inflation, $E_{t} p_{t+1}^{*}-p_{t}^{*}$, to be beyond its control, the domestic monetary authority seeks to minimize $p_{t}-E_{t-1} p_{t}, E_{t} p_{t+1}-p_{t}$, and $E_{t} e_{t+1}-e_{t}$ jointly in an effort to pursue its overall price-smoothing objective.

For the domestic authority, the model restrictions we have imposed and the uncovered interest parity condition together imply that foreign IS disturbances influence domestic aggregate demand only through instantaneous real-interestrate effects that are similar to those that arise as a result of the domestic money demand disturbance. That is, the foreign IS shock essentially affects domestic aggregate demand in the same manner as a domestic LM shock. For this reason, the optimal policy, given in $\left\langle 12>\right.$, is for the domestic authority to set $\theta_{1}$ at an infinite value to ensure a horizontal domestic LM schedule, which thereby eliminates the effects of both disturbances on the domestic price prediction error.

Equation $<12^{\prime}>$ indicates that $\hat{\theta}_{2}<1$ is the optimal policy for the domestic authority, so that any needed contemporaneous increase in the money stock is accompanied by a 
less-than-offsetting decrease in the money stock in the following period. This decrease is anticipated by agents, who thereby expect domestic price deflation in the next period. At the same time, however, they anticipate the domestic currency to appreciate, which thereby tends to offset the net effects on anticipated domestic consumer price inflation. The optimal value for $\theta_{2}$ given in $\left\langle 12^{\prime}\right\rangle$ causes these effects to net out exactly, so that domestic consumer price inflation is stabilized. Only if $\alpha=1$ or $\sigma_{\eta^{*}}^{2}=0$, so that domestic implications of the foreign IS shock are rendered irrelevant or non-existent, would a trend-stationary domestic monetary policy be optimal.

If we had considered the other pair of disturbances, $\eta_{t}$ and $\xi_{t}^{*}$, our results would have been reversed for the two countries. This implies that consideration of all four disturbances simultaneously would lead to base drift in either direction for both countries, depending on the relative magnitudes of the structural parameters and variances. Some degree of base drift and price-level non-trend-stationarity generally still would be optimal for each country, however.

In a separate appendix, which is available upon request, we have derived these explicit results in a tractable version of the general model. It can be shown, however, that the settings $\theta_{2}=1$ and $\theta_{2}^{*}=1$ fail to satisfy first-order conditions for optimal policies in the version of the model in which $a>0$. Consequently, the basic result that non-trend-stationary policymaking is optimal in a two-country framework extends beyond the special case we have considered. The linkages among the economies and the resulting feedback effects are much broader in scope in the more general model. Nevertheless, the essential explanation for the optimality of non-trend-stationary money stocks and prices parallels the rationale that emerges from our simpler expositional framework: efforts by monetary authorities to smooth both home goods prices and consumer prices must entail minimizing variations in home price prediction errors, home anticipated inflation, and anticipated home exchange-rate depreciation. If central banks follow monetary rules in which they optimally condition the contemporaneous money stock to home nominal interest rates and optimally adjust the trend path of the money stock, then a natural tension develops from the shortage of instruments relative to the total number of implicit

price-related targets. This international-based tension can induce price-level non-trend-stationarities irrespective of purely domestic central bank concerns with interest-rate smoothing (Goodfriend, 1987, 1991), monetary smoothing (VanHoose, 1989), or exchange-rate smoothing (Sephton, 1989).

\section{Implications of Broadened Monetary Rules}

One objection to the results of the last section is that they rely on the fact that the nations' 
central banks condition their policies only on interest rate innovations and on lagged innovations in their nations' money stocks. In theory, of course, central banks could adjust their money supply policies in response to a variety of instruments, such as prices or output (at least, in the more general case in which $a>0$ ). Nevertheless, real-world constraints on contemporaneous data availability typically lead monetary authorities to use interest-rate or lagged monetary innovations as their primary monetary policy guides.

This does not, however, preclude the possibility that central banks could condition their policies on exchange-rate, foreign interest-rate, or foreign monetary innovations. ${ }^{1}$ Consider, for instance, an amended monetary policy rule in which the domestic monetary authority adjusts the domestic money supply to lagged foreign money-stock innovations as well as to domestic interest-rate and lagged money-stock innovations:

$<16>\quad m_{t}=m_{t-1}+\theta_{1}\left(r_{t}-E_{t-1} r_{t}\right)-\theta_{2}\left(m_{t-1}-E_{t-2} m_{t-1}\right)-\theta_{3}\left(m_{t-1}^{*}-E_{t-2} m_{t-1}^{*}\right)$,

At the same time, we assume that the foreign monetary authority uses the same money supply rule as before (equation $<6^{\prime}>$ ). This assumption is not crucial to our results that follow; it only simplifies the exposition.

If we assume that the domestic monetary authority sets its policies taking the choices of the foreign authority as given, then for our restricted model $\left(d_{2}=0, d_{4}=1, a=0\right)$ we can obtain the following solutions for the optimal domestic policy choices:

$<17>$ $\hat{\theta}_{1}=\infty$

$<17^{\prime}>$

$\hat{\theta}_{2}=1$

$<17^{\prime \prime}>$

$\hat{\theta}_{3}=-\left[\left(\alpha \theta_{1}^{*}\right)\left(\beta_{1}+\alpha^{2} \beta_{2}\right)\right]^{-1}(1-\alpha) \beta_{1}\left\{\left(\theta_{1}^{*}+b\right)+\left[1-\left(1-\theta_{2}^{*}\right) \theta_{1}^{*}\right]\right\}$,

where $\theta_{1}^{*}$ and $\theta_{2}^{*}$ are taken as given by the domestic authority but in equilibrium will be equal to $\hat{\theta}_{1}^{*}=-b$ and $\hat{\theta}_{2}^{*}=1-[b(2 \alpha-1)]^{-1}(1-\alpha)\left(1-b \alpha \hat{\theta}_{3}\right)=1+\left\{\alpha b\left[\beta_{1}+(2 \alpha-1) \beta_{2}\right]\right\}^{-1}(1-$ $\alpha)\left(\beta_{1}-\alpha \beta_{2}\right)$. These policy settings again yield zero loss levels in both economies.

By adjusting the domestic money stock to foreign money innovations, the domestic central bank can achieve trend-stationarity of money and domestic prices. The explanation for this result is straightforward. Domestic conditioning to foreign monetary innovations relates the domestic money stock to the intertemporal evolution of foreign policy choices. Consequently, this additional policy instrument gives the domestic monetary authority another degree of freedom in aiming at its intertemporal policy objective.

To see this, consider how policy choices work in the model. As before, the optimal setting 
of the $\theta_{1}$ parameter minimizes the contribution of disturbances to the variance of domestic price prediction errors. This leaves the $\theta_{2}$ and $\theta_{3}$ parameters to minimize the variance of anticipated domestic consumer price inflation. Setting $\theta_{2}$ equal to one ensures that the domestic component of anticipated consumer price inflation is stationary. This leaves the choice of the $\theta_{3}$ parameter to determine the domestic-foreign interest-rate differential, which, via the uncovered interest parity condition, defines the optimal degree of anticipated exchange-rate depreciation consistent with minimization of the variance of anticipated domestic consumer price inflation. Essentially, conditioning the domestic money stock on foreign monetary innovations gives the domestic authority a sufficient number of independent instruments to take into account the tradeoff between anticipated domestic price inflation and anticipated exchange rate depreciation while preserving a trend-stationary path for domestic prices.

Alternative policy options would be to link the domestic money stock to foreign interest-rate innovations or to exchange-rate innovations. Because of uncovered interest parity, however, the domestic monetary authority would be unable to aim either of these instruments independently at its intertemporal objectives. Furthermore, conditioning domestic monetary policies on foreign interest innovations or to exchange-rate innovations would represent only an additional contemporaneous policy linkage and hence would fail to add an additional dimension along which domestic monetary policy could address the intertemporal nature of its objectives. Consequently, these alternative instrument choices do not, in the present model, permit the domestic monetary authority to minimize its intertemporalloss. ${ }^{2}$

Our analysis has focused solely on how trend-stationarity may be obtained by the domestic authority. The foreign authority could, of course, include domestic monetary innovations in its money supply rule. Then it also could layout a trend-stationary money stock path without incurring greater variability of its own prices.

Nevertheless, our restriction on the foreign authority's instruments implies that it must follow a non-trend-stationary policy rule. Furthermore, the use of foreign variables by the domestic authority (i.e. setting a non-zero, endogenous value for $\theta_{3}$ ) yields an interdependence among instrument settings that causes the equilibrium degree of foreign non-trend-stationarity to depend on domestic policy weights. Yet it should be noted that coordinating responses to lagged foreign monetary innovations would provide no additional benefit to either authority, because insular policymaking minimizes losses at zero in each regime we have considered.

The key point, however, is that if international interdependence is a reason for base drift and price-level non-trend-stationarity, the means for a central bank to attain monetary and price-level stationarity is to use the information content imbedded in foreign monetary 
innovations as a guide to determining home monetary policies. Certainly, there have been movements in recent years towards greater attention by monetary authorities to the spillover effects that foreign policy decisions exert on their home economies. Nonetheless, home political considerations can constrain the extent to which central banks are willing to allow foreign policies to affect home policy decisions. To the extent that central banks permit such considerations to restrain their actions in a more integrated world economic system, base drift and price-level non-trend-stationarities invariably will emerge from the international monetary policy process.

\section{Conclusion}

This paper has considered a symmetric two-country, flexible-exchange-rate model in which central banks simultaneously condition home monetary aggregates on home interest rates and determine whether or not these aggregates follow stationary time paths. It has been shown that this approach to policymaking, if it is aimed toward smoothing home-country output prices and consumer prices, generally induces central banks to choose non-trend-stationary time paths for monetary aggregates and prices. The reason is that a desire to minimize anticipated home consumer price inflation produces a tension between the need to minimize both the variance of anticipated home inflation and the variance of anticipated exchange rate depreciation. This tension induces central banks to balance one objective against the other by allowing sufficient degrees of base drift of their money stocks.

In principle, however, central banks can optimally follow trend-stationary monetary policies by incorporating foreign monetary innovations directly into their money supply rules. This would provide them with a sufficient number of instruments to overcome the tension among price-smoothing objectives that otherwise emerges as a result of international interdependence. The existence of structural linkages among economies requires direct recognition of these linkages in the conduct of monetary policy, unless central banks are willing to accept base drift and price-level non-trend-stationarities as incidental outcomes of purely insular policy procedures.

\section{Acknowledgments}

This paper has benefited from helpful comments received from Patrick Conway, Jürgen von Hagen, Chris Waller, and two anonymous referees. We also are grateful to Robert Toutkoushian for his assistance. The authors, however, are responsible for any errors 


\section{Notes}

1. We are grateful to a referee for suggesting that we explore this issue.

2. Specifically, including a term such as $\theta_{4}\left(e_{t}-E_{t-1} e_{t}\right)$ in the monetary rule produces very complicated loss expressions in which the $\theta_{1}$ and $\theta_{4}$ parameters enter in similar fashions. It can be shown that both of these parameters cannot be set simultaneously by the domestic authority to zero out the loss. Coordinated exchange-rate smoothing by the two authorities conceivably could minimize the loss function; in fact, analysis of exchange-rate smoothing in the context of this model leads to some potentially fascinating coordination issues. Yet these also are very complex issues that we plan to pursue in a separate paper.

\section{References}

Basar, Tamer, Stephen Turnovsky and Vasco d'Orey, 'Optimal Strategic Monetary Policies in Dynamic Interdependent Economies,' Journal of Economic Dynamics and Control, June 1986, 10: 15-19.

Bordo, Michael, Ehsan Choudhri and Anna Schwartz, 'Money Stock Targeting, Base Drift, and Price-Level Predictability,' Journal of Monetary Economics, March 1990, 25: 253-272.

Cooper, Richard, 'Economic Interdependence and Coordination of Economic Policies,' in R. W. Jones and P. B. Kenen, eds, Handbook of International Economics, Volume II, Elsevier Science Publishers: Amsterdam, 1985: 1195-1234.

Goodfriend, Marvin, 'Interest Rate Smoothing and Price Level Trend-Stationarity,' Journal of Monetary Economics, May 1987, 19: 335-348.

Goodfriend, Marvin, 'Interest Rates and the Conduct of Monetary Policy,' Carnegie Rochester Series of Public Policy, Spring 1991, 34: 7-30.

Poole, William, 'Optimal Choice of Monetary Policy Instruments in a Simple Stochastic Macro Model,' Quarterly Journal of Economics, 1970, 84: 197-216.

Sephton, Peter, 'A Note on Exchange Rate Trend-Stationarity,' International Economic Journal, 1989, 3: 73-77.

Turnovsky, Stephen and Vasco d'Orey, 'Monetary Policies in Interdependent Economies with Stochastic Disturbances: A Strategic Approach,' The Economic Journal, September 1986, 96: 696-721.

Turnovsky, Stephen and Vasco d'Orey, 'The Choice of Monetary Instruments in two Interdependent Economies under Uncertainty,' Journal of Monetary Economics, January 1989, 23: 121-133.

Turnovsky, Stephen, Tamer Basar and Vasco d'Orey, 'Dynamic Strategic Monetary policies and 
Coordination in Interdependent Economies,' American Economic Review, June 1988, 78: 341-361.

VanHoose, David D., 'Monetary Targeting and Price Level Non-Trend-Stationarity,' Journal of Money, Credit, and Banking, May 1989, 21: 232-239.

Walsh, Carl E., 'In Defense of Base Drift,' American Economic Review, September 1986, 76: 692-700.

Walsh, Carl E., 'Issues in the Choice of Monetary Policy Operating Procedures,' in William Haraf and Phillip Cagan, eds, Monetary Policy for a Changing Financial Environment, AEI Press: Washington, D.C., 1990. 